\title{
THE PATTERN OF DEFOLIATION OF COCKSFOOT BY GRAZING SHEEP
}

\author{
P. J. McIvor and B. R. WATKIN \\ Department of Agronomy, Massey University, Palmerston North
}

\section{Abstract}

The pattern of defoliation of cocksfoot by Romney sheep at two stocking rates (approximately 36 and 80 sheep/ha) was studied in the autumn. After an autumn "flush" of growth, pasture availability, - pasture height and green leaf length showed a rapid then steady decline during the grazing period. The length of green leaf removed per defoliation was closely related to the length of leaf available i.e.,-the shorter the length available, the shorter the length removed. The proportion of green leaf length removed, however, showed little change over. the grazing period.

Tillers were, grazed every 5 or 6 days in the high-stocked treatment and every 7 or 8 days in the medium-stocked treatment. These were generally the taller tillers, particularly in the mediumstocked treatment.

Evidence of preferential grazing of different aged tillers was not obvious. However, towards the end of the experimental period the youngest tillers in the, medium-stocked treatment were grazed less frequently but more severely than, older tillers. In the- highstocked treatment the youngest tillers were less severely- grazed than older tillers.

Preference for the youngest leaves on a tiller was evident in all treatments.

The mean liveweight of sheep increased on the medium-stocked treatment but decreased slightly. on the high-stocked treatment.

The plant and animal responses recorded are discussed.

\section{INTRODUCTION}

MANY WORKERs have described the effects of stocking rates on animal performance,- as seen in the reports of Morley and Spedding (1968) and Cowlishaw (1969), but there still remains limited information on the reasons for fhe differences recorded. One of the major factors involved may well be the pattern of defoliation by the grazing animal, which affects the quantity, the quality, and the rate of prehension of the pasture. Spedding (1965) . reported that as stocking rate increased so did the frequency and severity of defoliation of individual tillers in a setstocked sward. Greenwood and Arnold (1968) also showed that the frequency of defoliation of individual plants in an emerging 
annual grass sward declined as the amount of available herbage increased. However, other factors, such as pasture height, density, species and growth form, may modify this patter?. Morris (1969), for example, found that, although the frequency of defoliation of cocksfoot tillers increased as leaf area index " declined, the severity of defoliation did not vary significantly.

This paper reports a brief study of the defoliation pattern of a cocksfoot sward grazed at two stocking rates.

\section{MATERIALS AND METHODS}

Four paddocks, two of 0.18 ha and two of 0.09 ha, were fenced in early March 1970, on a four-year-old sward of cocksfoot (Dactylis glomerata cv. 'Grasslands Apanui'), at Palmerston North. For 4 years prior to the experiment the paddocks received an annual application of approximately $700 \mathrm{~kg} / \mathrm{ha}$ of urea in three dressings applied in August, November and March. Applications of $627 \mathrm{~kg} / \mathrm{ha}$ of superphosphate and $250 \mathrm{~kg} / \mathrm{ha}$ of muriate of potash were also made annually. On March $9,1970,125 \cdot \mathrm{kg} / \mathrm{ha}$ of urea were applied. At the end of the summer (February 1970) the paddocks were grazed and mown to remove. any dead material and provide an even sward, and then closed to permit autumn regrowth. On March 31, seven mature Romney ewes were allocated to each paddock to give a similar liveweight distribution and' mean per plot: The mean stocking' rates compared during the experimental period were 36.1 and 79.7 sheep per hectare, hereafter called the medium-stocked and high-stocked treatments. The 'animals were removed on May' 14:

The method of tiller identification was similar to that described by Hodgson and Ollerenshaw (1969) . . In each paddock 20 tillers were randomly located in each of 10 transects and identified using loops of plastic-covered wire, giving a total of 200 tillers per paddock. Tillers with more than 'two leaves were classified as "old" and those with two leaves were classified as "young" tillers. Three weeks after the commencement of the experimen! further: tillers with two leaves were marked and classified as "youngest" tillers.

During the experimental period of six weeks, all tillers were examined every 2 to 4 days and recorded as, either grazed or not grazed. The particular leaf grazed was also recorded. On each examination every grazed leaf was slit terminally with a needle for a length of 3 to $5 \mathrm{~mm}$ parallel to the leaf veins. The presence or absence of the slit at succeeding observations indicated whether or not the leaf had been grazed. 
Estimates of pasture height were determined at 2- to 4-day intervals by measuring the vertical height of undisturbed tillers from ground level at 60 sites per paddock. The maximum length of leaf per marked tiller (G.L.L.), from ground level to leaf tip, was also recorded at similar frequency and intensity.

The pattern of leaf selection within tillers was examined by counting the number of tillers with leaves grazed, and those with leaves ungrazed, in three positions: 1 - youngest leaf; 2 - next youngest leaf: 3 - an older leaf.

At weekly intervals pasture quadrats $(1.3$ by $0.3 \mathrm{~m})$ were cut to ground level in each plot, 6 from each of the medium-stocked paddocks and 4 from each of the high-stocked paddocks, using a shearing handpiece to estimate pasture availability. Herbage was weighed, bulked and subsampled for dry matter determinations and botanical analyses. Estimates of pasture growth under these continuously stocked conditions were made every two weeks, using the Australian "difference" technique as described by Lynch (1966). On these occasions 50 tiller cores were taken per plot with a $5 \mathrm{~cm}$ diameter core sampler and the tillers counted.

The sheep were weighed on three occasions during the experimental period and three sheep in each treatment were fitted with "Kienzle" vibrarecorders (Allden, 1962) to determine grazing time. After 3 weeks the recorders were fitted to different sheep to minimize between-sheep variation.

\section{RESULTS}

Changes in pasture availability through\&t the grazing period are shown in Fig. 1. From similar levels at the commencement of the experiment, the availability rose sharply on both treatments and then fell steadily until the end of the period.

The daily growth rate of the pastures (Table 1) declined from high levels initially to low levels towards the end of the experiment. The rate of decline appeared to be greater on the highstocked than on the medium-stocked treatment.

TABLE I: MEAN DAILY GROWTH RATES (kg/ha day)

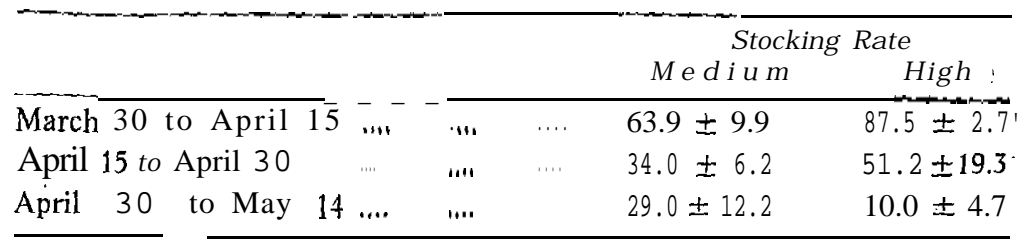




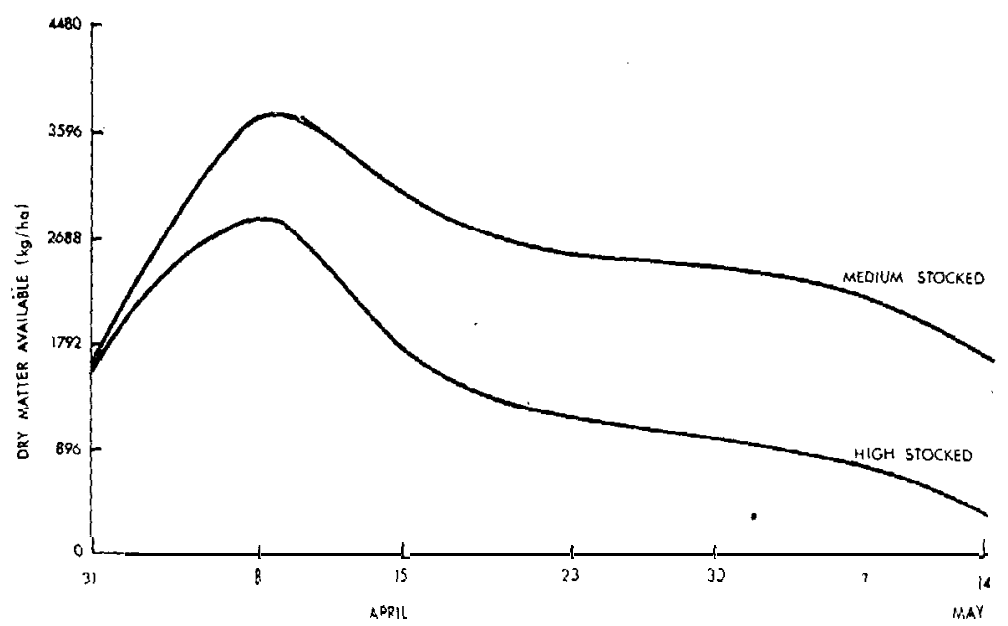

Fig. 1: Total dry matter available.

The botanical composition of the pastures, presented in Table 2 , shows that cocksfoot was the major component of the herbage.

The changes in height of the pasture and green leaf length (G.L.L.) of the tillers, presented in Fig. 2, show that following an initial increase there was a sharp then a steady decline in both parameters towards the end of the experiments.

From similar densities at the start of the experiment, tiller numbers increased to a much greater extent in the mediumstocked treatment than in the high-stocked treatment (Table 3). This increase was due to a rise in both cocksfoot tillers and those of the contaminants, mainly Poa spp. However, these latter species were a small proportion of the total dry weight because of their small tiller size.

Tillers were grazed every 5 or 6 days under the high-stocked treatment and every 7 or 8 days under the medium-stocked treatment, the difference being significant $(\boldsymbol{P}<0.05)$.

TABLE 2: BOTANICAL COMPOSITION ( $\%$ GREEN DRY MATTER)

\begin{tabular}{lcccc}
\hline \multirow{2}{*}{ Dnfe } & \multicolumn{2}{c}{ Medium-stocked } & \multicolumn{2}{c}{ High-stocked } \\
& Cocksfoot & 0 ther spp. & Cocksfoot & Other spp. \\
\hline March 31 & 87 & 13 & 81 & 19 \\
April 24 & 80 & 20 & 80 & 20 \\
May 14 & 77 & 23 & 72 & 28 \\
\hline
\end{tabular}




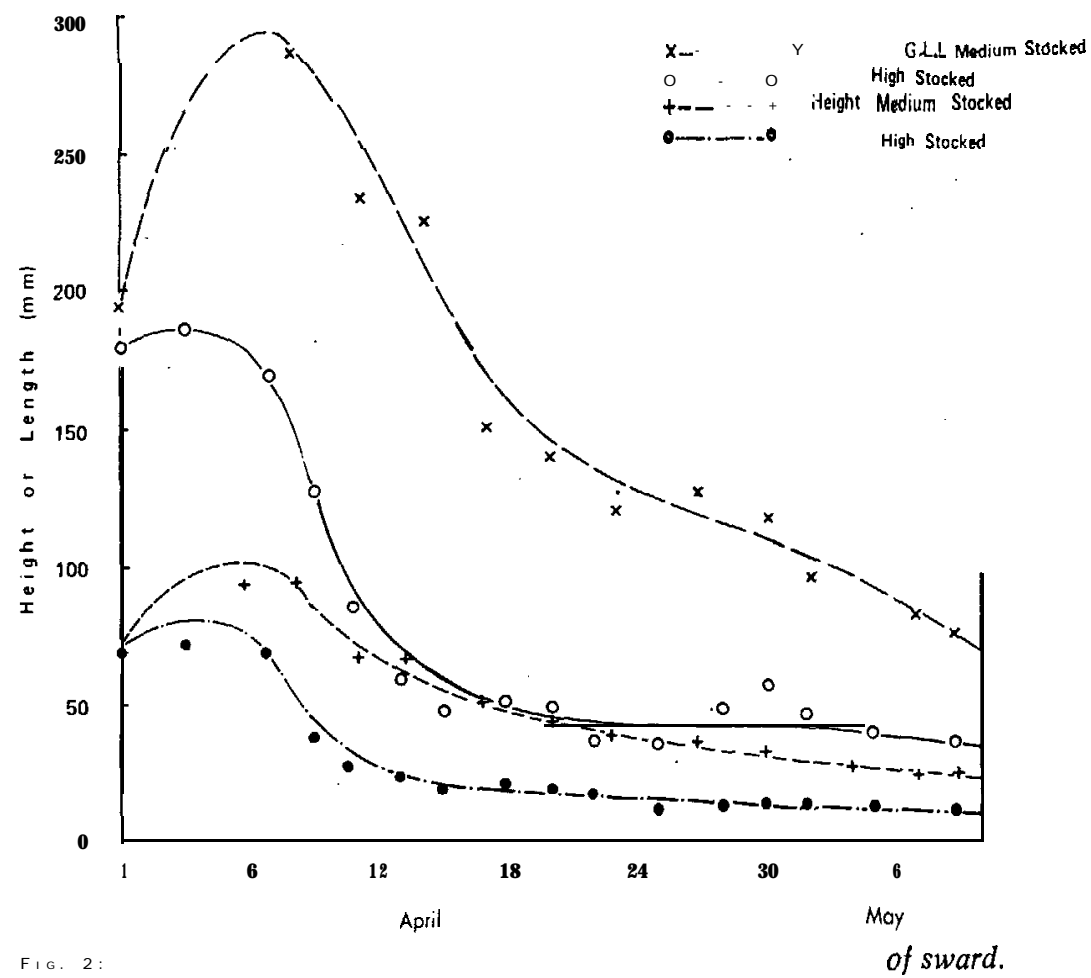

From the measurements made at each observation it was found that the G.L.L. and height of the tillers which were subsequently grazed were generally greater than those of the ungrazed tillers. This effect occurred more frequently in the medium-stocked than in the high-stocked treatment.

As shown in Fig. 3 there was a decline with time in the G.L.L. per tiller removed per defoliation by the sheep on both treatments. However, in terms of the percentage of G.L.L. removed there was little difference between the medium- and high-stocked treatments apart from a sharp but temporary increase in late April in the high-stocked treatment. Approximately 33 and $36 \%$ of the G.L.L. was removed per defoliation on the mediumstocked and high-stocked treatments, respectively, throughout the experimental period.

There was no striking evidence of preferential grazings of any particular category of tillers, except on the medium-stocked treatment in the latter half of the experimental period when the 
TABLE 3: TILLER COUNTS

(hundreds of tillers $/ \mathrm{m}^{*}$ )

\begin{tabular}{|c|c|c|c|c|c|c|}
\hline Date & Cocksfoot & $\begin{array}{c}\text {-M edium-stocked } \\
\text { O ther spp. }\end{array}$ & Dead & Cocksfoot & $\begin{array}{l}\text { High-stocked } \\
\text { O ther spp. }\end{array}$ & Dead \\
\hline $\begin{array}{l}\text { March } 29 \\
\text { April } 25\end{array}$ & $\begin{array}{l}51.5 \pm 5.0 \\
71.2 \pm 9.5\end{array}$ & $\begin{array}{l}14.4 \pm \quad \pm .2 \\
18.6 \pm 6.0\end{array}$ & $\begin{array}{l}5.4 \pm 2.1 \\
4.8 \pm 0.5\end{array}$ & $\begin{array}{l}58.5 \pm 8.0 \\
60.8 \pm 2.9\end{array}$ & $\begin{array}{l}16.6 \pm 9.2 \\
25.4 \pm 8.6\end{array}$ & $\begin{array}{l}1.3 \pm 0.9 \\
4.2 \pm 0.7\end{array}$ \\
\hline May 12 & $118.0 \pm 12.9$ & $33.3 \pm 16.3$ & $0.8 \pm 0.7$ & $71.2 \pm 3.2$ & $38.8 \pm 6.4$ & $3.2 \pm 0.3$ \\
\hline
\end{tabular}




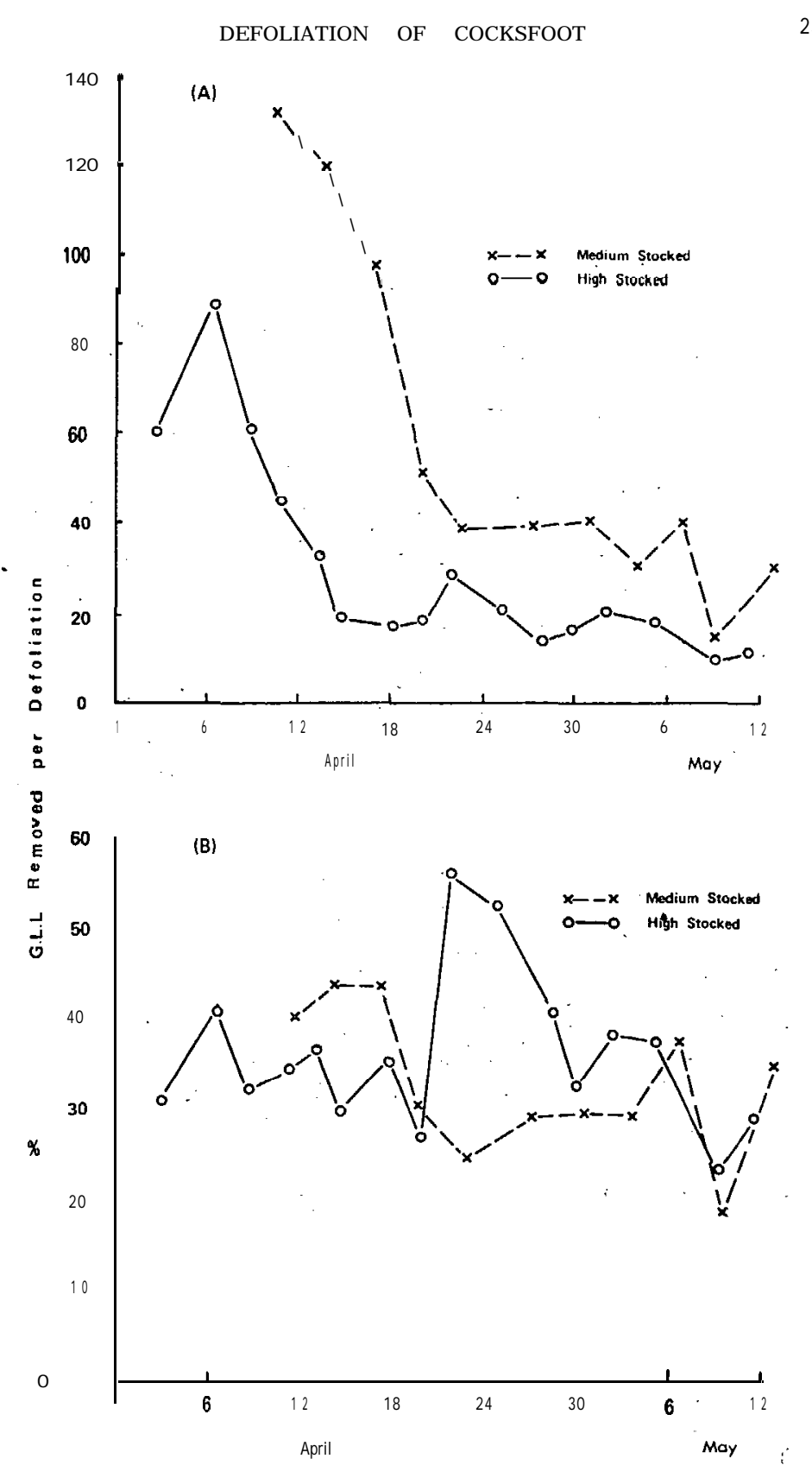

FIG. 3: Severity of defoliation of individual tillers. (A) M ean G.L.L. removed $(\mathrm{mm})$ and $(B) \%$ of G.L.L. removed, at a single defoliation. 
"youngest" tillers were grazed less frequently than the "young" and "old" tillers. Grazing intensity (percentage G.L.L. removed) tended to be less severe on the "youngest" tillers during this period in the high-stocked treatment but more severe in the medium-stocked treatment.

The younger leaves (categories 1 and 2) were equally acceptable to and preferred by the animal compared with the older green leaves (category 3) which were strongly rejected at both stocking rates.

Sheep liveweights are -presented in Table 4 and show that under the high-stocked treatment the sheep tended to lose weight ' while those on the medium treatment tended to gain in weight over the experimental period.

TABLE 4: MEAN SHEEP LIVEWEIGHTS (kg)

\begin{tabular}{lcc}
\hline & Medium-stocked & High-stocked \\
\hline March 31 & 42.9 & 42.0 \\
April 22 & 46.2 & 40.2 \\
May 15 & $49.2 \pm 1.6$ & $39.2 \pm 0.80$ \\
\hline
\end{tabular}

Sheep on the high-stocked treatment tended to graze for a longer period each day (mean $9.22 \mathrm{~h}$ ) than those on the mediumstocked treatment (mean $8.43 \mathrm{~h}$ ). The time was also longer in the second half of the experimental period than in the first.

\section{DISCUSSION}

The decline in herbage available and in pasture height at each stocking rate was due primarily to defoliation by the grazing sheep and to the declining growth rate following the autumn flush. Other contributing factors such as treading damage by sheep and low L.A.I. of the pasture, particularly under the high-stocked conditions late in the experimental period, are also recognized. Losses by leaf senescence were considered to be small.

An asymptotic relationship has been. reported between animal performance and pasture availability, with maximum performance occurring. when availability reached the range of 1500 to 2000 kg/ha (Willoughby, 1959; Allden, 1962; Arnold, 1963). The performance of the animals in this trial supports this hypothesis, since sheep on the medium-stocked treatment had more than $1500 \mathrm{~kg} / \mathrm{ha}$ of pasture available and gained weight while the sheep on the high-stocked treatment had less than 
$1500 \mathrm{~kg} / \mathrm{ha}$ for much of the experiment and lost weight. However, to suggest that liveweight gain merely reflects pasture availability may be an oversimplification. Some investigators have found little or no relationship between intake and pasture availability, but have found spatial arrangement, height and density of the pasture to be closely related to the rate of intake (Wheeler et al., 1963; Allden and Whittaker, 1970). Allden and Whittaker (1970) found that as the height of the pasture (Wimmera ryegrass) decreased from 7.7 to $3.7 \mathrm{~cm}$ the rate of intake declined seven-fold. In this trial with cocksfoot the change in pasture height of the medium-stocked treatment during the experiment was of a similar order of magnitude. However, although intake measurements were not made, the rate of liveweight gain per animal declined only slightly, suggesting that intake was maintained at a satisfactory level. This was probably due to the increase in tiller density recorded over this period and to the increase in grazing time per day recorded, and serves to highlight the problem of trying to establish simple relationships in dynamic situations.

The increase in grazing time recorded on the high-stocked treatment reflected the shortness of the pasture and its reduced availability. A similar result was reported by Arnold (1963).

Estimates of the frequency of defoliation in this experiment were similar to those observed by Hodgson (1966) and Hodgson and Ollerenshaw (1969) on continuously grazed ryegrass swards in England. Hodgson found that defoliation occurred every 5 to 8 days at high stocking rates (77 to 91 sheep/ha), and reported little change in frequency at medium stocking rates (defoliation every 4 to 7 days at 29 to 47 sheep/ha). However, the present experiment did show a significant drop in defoliation frequency at the lower stocking rate (defoliation every 7 or 8 days at 36 sheep/ha). This pattern therefore agrees with observations made by Morris (1969) of an inverse relationship between the frequency of defoliation and the leaf area index and availability of the sward.

The inechanism of this frequency change is suggested by Allden and Whittaker (1970) to be due to a reduction in the size of bite being taken as pastures become shorter, necessitating a change in grazing behaviour as the animal endeavours to maintain intake. Under such conditions grazing sheep have been observed to increase the rate of biting and the grazing times per day (Allden and Whittaker, 1970; Arnold, 1963; Arnold and Dudzinski, 1966). Such changes would lead to an increase in the 
number of bites per day which could result in a more frequent defoliation of the individual tillers of a sward.

It was found that the sheep generally grazed the taller tillers, particularly at the lighter stocking rate. The length of green leaf removed per defoliation appeared to be closely related to the initial green leaf length and height of the tiller. This is seen in the close similarity between the curves in Fig. 3 (A). Allden and Whittaker (1970) have shown that the size of bite of grazing sheep declines as the length of tiller declines. While the measure of G.L.L. (mm) removed is not the same as the size of bite of the sheep, the changes in the length of leaf removed probably reflect changes in the size of bite.

'Since the length of leaf removed appears to be closely related to the G.L.L. of the tiller before grazing, it is not surprising that the percentage G.L.L. removed showed little change throughout the experimental period or between stocking rates. These results contrast with those of Hodgson (1966) for a perennial ryegrass sward where, as stocking rate increased, both the length of G.L.L. removed and the percentage of G.L.L. removed also increased.

At greater heights of pasture than those examined here, percentage G.L.L. removed might be expected to change. For example, in another experiment (McIvor, unpubl. data) on cocksfoot, the percentage G.L.L. removed was observed to be approximately $25 \%$ when the pastures were $110 \mathrm{~mm}$ high and increased to $30 \%$ when the height declined to $35 \mathrm{~mm}$. The results of the present study show that where the height declines below 40 to $50 \mathrm{~mm}$, the severity of defoliation does not alter greatly, at least for a considerable period during subsequent grazing. The changing growth form of tillers - i.e., towards a more prostrate growth habit under close grazing - may well restrict a more severe defoliation with declining height.

The only major difference in the pattern of defoliation of tillers of different ages was in the frequency of defoliation in the medium-stocked treatment. The "youngest" tillers were only defoliated every 10 or 11 days while the other tillers were defoliated every 6 or 7 days. It is suggested that this was a function of low accessibility of the "youngest" tillers in the canopy as G.L.L. measurements showed they were approximately $70 \mathrm{~mm}$ long compared with $100 \mathrm{~mm}$ for the older tillers. When grazing did occur, it tended to be more severe than for the older tillers. In the high-stocked treatment there was no difference in the frequency of defoliation of the different aged tillers but the 
"youngest" tillers were less severely defoliated. As G.L.L. between these tiller categories showed no difference in this treatment, it is suggested that this lower severity of defoliation was also due to low accessibility but for a very different reason, namely, the observed development of a more prostrate habit in the "youngest" tillers and therefore greater difficulty in prehension.

At both stacking rates, and over the range of pasture heights recorded, the animal preference for the youngest leaves on the tiller was maintained.

\section{REFERENCES}

Allden, W. G., 1962: Proceedings of the Australian Society of Animal Production, 4: 163-6.

Allden, W. G.; Whittaker, I. A., 1970: Australian Journal of Agricultural Research, 21: 755-66.

Arnold, G. W., 1963: Wool Technology and Sheep Breeding, JO: 17.9.

Arnold, G. W.; Dudzinski, M. L., 1966: Proceedings of the 10th International Grassland Congress: Helsinki, Finland.

Cowlishsw, S. J., 1969: Journal of the British Grassland Society, 24: 3. 207-14.

Greenwood, E. A. N.; Arnold, G. W., 1968: Journal of the British Grassland Society, 23: 144-7.

Hodgson, J., 1966: Journal of the British Grassland Society, 21: 258-63.

Hodgson, J.; Ollerenshaw, I. H., 1969: Journal of the British Grassland Society, 24: 206-34.

Lynch, P. B., 1966: N.Z. Department of Agriculture Bulletin 339.

Morley, F. H. W.; Spedding, C. R. W., 1968: Herbage Abstracts, 4: 279-87.

Morris, R. M., 1969: Journal of the British Grassland Society, 24: 65-70.

Spedding, C. R. W., 1965: Herbage Abstracts, 35: 77-84.

Wheeler, J. L.; Reardon, T. F.; Lambourne, L. J., 1963: Australian Journal of Agricultural Research, 14: 364-72.

Willoughby, W. M., 1959: Australian Journal of Agricultural Research, 10: $248-68$ 